Article

\title{
Tensile Properties and Microstructure of Single-Cellulosic Bamboo Fiber Strips after Alkali Treatment
}

\author{
Abeer Adel Salih *(D), Rozli Zulkifli ${ }^{\circledR}$ and Che Husna Azhari \\ Department of Mechanical and Manufacturing Engineering, Faculty of Engineering and Built Environment, \\ Universiti Kebangsaan Malaysia, Bangi 43600, Malaysia; rozlizulkifli@ukm.edu.my (R.Z.); \\ husna.azhari@gmail.com (C.H.A.) \\ * Correspondence: Abeer.salih@siswa.ukm.edu.my
}

Received: 20 February 2020; Accepted: 22 April 2020; Published: 28 April 2020

\begin{abstract}
The study systematically explored the effect of alkali concentration and soaking time on the microstructure and tensile properties of single-cellulosic Buluh Semantan. Scanning electron microscopy and tensile tests were conducted to determine the effects of different alkali treatments on the properties of the single-cellulosic bamboo fibers. In particular, the effects of $\mathrm{NaOH}$ concentration and soaking time on the tensile properties of the single-cellulosic bamboo fiber were investigated. The single-cellulosic bamboo fiber was immersed in 2, 4, 6, and $8 \mathrm{wt}$.\% aqueous $\mathrm{NaOH}$ solutions for soaking times of $1,3,6,12,18$, and $24 \mathrm{~h}$. The tensile properties of the fiber increased after each alkali treatment. The alkali concentration and soaking time significantly affected the fiber properties. The ultimate tensile strength of the single-cellulosic Buluh Semantan treated with $2 \mathrm{wt} . \% \mathrm{NaOH}$ for $12 \mathrm{~h}$ decreased to $214 \mathrm{MPa}$ relative to the fibers that experienced water retting. The highest tensile strength herein was $356.8 \mathrm{MPa}$ for the single-cellulosic fiber that was soaked for $12 \mathrm{~h}$ in $4 \mathrm{wt} . \% \mathrm{NaOH}$. Comparatively, the tensile strength of the single-cellulosic bamboo fiber that was soaked for $12 \mathrm{~h}$ in $8 \mathrm{wt} . \% \mathrm{NaOH}$ was $234.8 \mathrm{MPa}$. The tensile modulus of the single-cellulosic fiber was $12.06 \mathrm{GPa}$ after soaking in $8 \mathrm{wt} . \% \mathrm{NaOH}$ for $18 \mathrm{~h}$, indicating that a strong alkali treatment negatively affected the stiffness and suitability for use of the fibers in applications. The topography of the fiber surface became much rougher after the alkali treatments due to the removal of hemicellulose and other surface impurities. The alkali treatments substantially changed the morphology of the fiber surface, suggesting an increase in wettability.
\end{abstract}

Keywords: tensile strength; single fiber; bamboo strips; alkali treatment

\section{Introduction}

Currently, due to the increasing awareness of environmentally friendly biomaterials, natural fibers have gained widespread attention as a prospective alternative to synthetic fibers, for their composite applications in the construction and automobile industries [1,2]. The benefits of using natural lignocellulose fibers in place of traditional inorganic fibers made from fossil fuels relate to their specific properties, such as their light weight, low cost, high specific properties, low density, good thermal properties, eco-friendliness, and biodegradability [1]. They can also be used as a replacement for glass fibers during composite manufacturing [3,4]. Indeed, far-ranging studies on natural fibers, including sisal, flax, kenaf, and bamboo, demonstrate that natural fibers possess amazing potential as an effective reinforcing phase in composite materials [1]. The NF exhibits poor resistance to moisture, thus leading to high water absorption and poor mechanical properties and dimensional stability. Alkali treatment is common fiber treatment, to provide fiber/matrix adhesion and good 
mechanical properties of the composites [5,6]. Bamboo is the largest member of the grass family Poaceae, subfamily Bambusoideae, and tribe Bambuseae. In tropical areas, especially Asian countries, bamboo is a basic natural resource that plays an important role in people's daily lives and cultures because of its rapid growth, excellent flexibility, high strength, weight ratio, excellent specific strength, and high specific modulus [7,8]. Malaysia has classified bamboo into 59 species, of which 25 species have been introduced, while 34 species are indigenous $[9,10]$. The strength of bamboo generally increases with the thickening of its fiber walls, and maturity is reached in approximately three years [11,12]. In Asia, bamboo is widely used as a raw material for furniture, pulping, and handicrafts $[13,14]$. The bamboo culm is constructed in hollow cylinders, while internodes are the place where branches grow. Each section of the bamboo fiber has different properties. Different types of bamboo fibers vary in their properties due to differences in their length, diameter, constituent composition and lumen size. The term lignocellulose fiber includes all kinds of fibers that have major components comprising cellulose, hemicellulose, and lignin in different proportions depending on the type and source of the fiber $[15,16]$. The chemical components of bamboo fibers have been reported to include $73.83 \%$ cellulose, $12.49 \%$ hemicellulose, $10.15 \%$ lignin, $0.37 \%$ pectin, and $3.16 \%$ aqueous extract. Indeed, lignocellulose fibers are known to have a hydrophilic nature and are covered with pectin's and waxy substances, thus preventing the hydroxyl groups from reacting with polar and hydrophobic organic matrices. This fact leads to premature ageing by degradation and loss of strength of the final composite $[15,17]$. Retting, also called degumming, is the process of removing non-cellulosic materials attached to fibers, to release the individual cellulosic fiber. However, information on the effect of extraction methods on natural fiber properties is limited. Amel et al. [18] investigated the effect of different extraction methods on the tensile strength, morphology, chemical composition, and density of kenaf fibers. The different methods include crude, decorticated, water-retted, $5 \mathrm{wt}$ \% $\mathrm{NaOH}$-retted, and $5 \mathrm{wt}$ \% benzoate-retted methods. The water-retted fiber has the highest reported tensile strength of $426.05 \mathrm{MPa}$, while there is a slight difference in tensile strength between decorticated and NaOH-retted fibers (386.85 and 393.03 MPa, respectively). The hydrophilic nature of natural fibers may have disadvantages if they are used to reinforce hydrophobic polymeric matrices, because cellulose, as the main component of natural fiber, is cemented by matrix lignin, and hemicellulose functions as a weak boundary layer and reduces the adhesion between the fibers and polymeric materials [19]. Surface modification is necessary to improve the adhesion of fiber-polymeric materials, such as silane coupling agents [20], compatibilizers [21], alkali treatments [22-24], and heat treatments [25], which are often used to introduce a decreased number of polar groups and replace hydroxyl groups on bamboo fiber surfaces, as a means to decrease the water absorption and aggregation in the fiber [26]. Among all these treatments, mercerization or alkali treatments are versatile and bring about changes in the dimensions, fine structure, chemical composition, morphology, and crystalline component; they also improve the wettability and resin pick up of natural fibers, like coir, sisal, flax, and cotton. Alkali treatments improve the adhesion between these hydrophilic fibers and the hydrophobic matrix by roughening and exposing additional cellulose on the surface. Alkali treatments are effective in producing high-quality fibers at experimental and commercial scales, because they enable the disruption of hydrogen bonding in network structures, resulting in an increase in the surface roughness and removal of hemicellulose and lignin from the fiber surface. The alkali treatment modifies the chemical constituents, resulting in changes in the mechanical properties, surface roughening, crystallinity, and thermal behavior of the fibers. The literature reveals that $\mathrm{NaOH}$ treatment removes the binding materials, depending on the treatment time, concentration of $\mathrm{NaOH}$, treatment temperature, and liquor ratio [3]. Studies on the effect of $\mathrm{NaOH}$ treatment on the properties of bamboo fiber have already been performed by researchers, such as Hong et al. [27], who studied the tensile properties of individual bamboo fibers by using $\mathrm{NaOH}$ solutions with concentrations ranged $(6,8,10,15$, and $25 \mathrm{wt}$.\%) for $2 \mathrm{~h}$. The bamboos were cut into strips at $30 \mathrm{~mm}$ longitudinally and $2 \times 2 \mathrm{~mm}^{2}$ in the cross-section. The tensile strength and modulus of elasticity decreased for the bamboo strips treated with alkali concentrations that were greater than $8 \mathrm{wt} . \%$. The effect of the $\mathrm{NaOH}$ concentration on the tensile strength was negligible, but the 
influence on the modulus of elasticity was significant. Wang et al. [1] investigated the influence of alkali concentration on the thermomechanical properties of bamboo fibers. The alkali concentrations were 1 , 4 , and 7 wt. $\% \mathrm{NaOH}$ solutions at room temperature, and the treatment time was $1 \mathrm{~h}$. Compared with that for the untreated fibers, there was an improvement in the average tensile strength of the fibers after an alkali treatment at a concentration of $4 \mathrm{wt}$.\%, which can be attributed to the formation of an effective contact area being available for excellent bonding with the matrix after treatment, whereas the high concentration used in the treatment caused a decrease in the tensile strength. This paper investigates the effects of the alkali concentration and soaking time on bamboo strips. The morphologies of the fracture surfaces were examined by using scanning electron microscopy (SEM).

\section{Experimental Methods}

\subsection{Materials}

The bamboo fiber species used in this study was Gigantochloa scortechinii, which is commonly known as semantan bamboo and was obtained from Pahang, Malaysia. This fiber was subjected to a water-retting process before being supplied to the laboratory. The bamboo fibers were then dried under the sun before they were manually extracted. The strips were manually extracted from the bamboo culm after water retting. All fibers were obtained from the outer layer of the bamboo stem, and to ensure consistency, only fibers from the same bunch were used. The sodium hydroxide $(\mathrm{NaOH})$ used in this study was supplied by Mylab company, Malaysia, in a $1 \mathrm{~kg}$ container with a small pallet shape.

\subsection{Fiber Diameter}

The bamboo fiber was selected and separated from the bundle fiber and finally separated into single fibers. The bamboo fiber diameter was measured at $4.5 \mathrm{~mm}$ intervals, along its length, using a Leica Stereo Microscopic video analyzer 2000 (Model 250 D, Selangor, Malaysia). The mean diameter of single bamboo fiber strips was measured from the average of ten fibers, in which the diameter for every fiber was the average value of the diameter measured ten times at $4.5 \mathrm{~mm}$ intervals along the fiber length. The measurement was replicated three times for each treatment condition.

\subsection{Alkaline Treatment}

For the first step, the bamboo fiber strips were subjected to a water-retting process before they were supplied to the laboratory. The selected Buluh semantan strips were cut into an average length of $240 \mathrm{~mm}$, with a diameter of $95.12 \mu \mathrm{m}$, and soaked in an alkaline aqueous solution, at different soaking times, at room temperature. Mishra et al. [28] reported that the $\mathrm{NaOH}$ concentration can vary from 1 to $10 \mathrm{wt}$ \%. The researchers who published [23,29] reported that high concentrations of $\mathrm{NaOH}$ can worsen the mechanical properties of bamboo fiber strips. In this work, four different alkaline concentrations were prepared $(2,4,6$, and $8 \mathrm{wt} . \%)$. After the treatment, the bamboo fiber strips were washed, using fresh water, to remove the alkali content from them. A litmus paper was used to confirm that the fibers were neutralized. This was followed by drying under the sun for approximately two days before they were dried in an oven at a temperature of $60^{\circ} \mathrm{C}$ for $24 \mathrm{~h}$. The dried bamboo fiber strips were then kept in a sealed plastic bag, to avoid water absorption from the atmosphere before tensile testing.

\subsection{Fabrication of the Samples}

Before folding the adhesive tapes, the bamboo fiber strips were further glued with a cyanoacrylate adhesive liquid, to prevent the fibers from slipping during the tests and to enhance the adhesion of the fibers to the tape surface. All samples were fixed to a gauge length of $210 \mathrm{~mm}$. Figure 1 shows a schematic diagram of the sample preparation method for the testing. The samples were then clamped tightly on a 2 kN Zwick/Roell machine (Zwick company, Berlin, Germany) (Figure 1e). The tensile test was carried out according to the ASTM-D 3822-07 standard. The crosshead speed was set to $1.5 \mathrm{~mm} / \mathrm{min}$. The tests were performed on fibers with 2, 4,6, and 8 wt. $\% \mathrm{NaOH}$ treatments. Seven samples from 
each condition were tested, and the average values were reported by calculating the maximum of five values, because we excluded from analysis the samples that broke near the edge of the clamps.
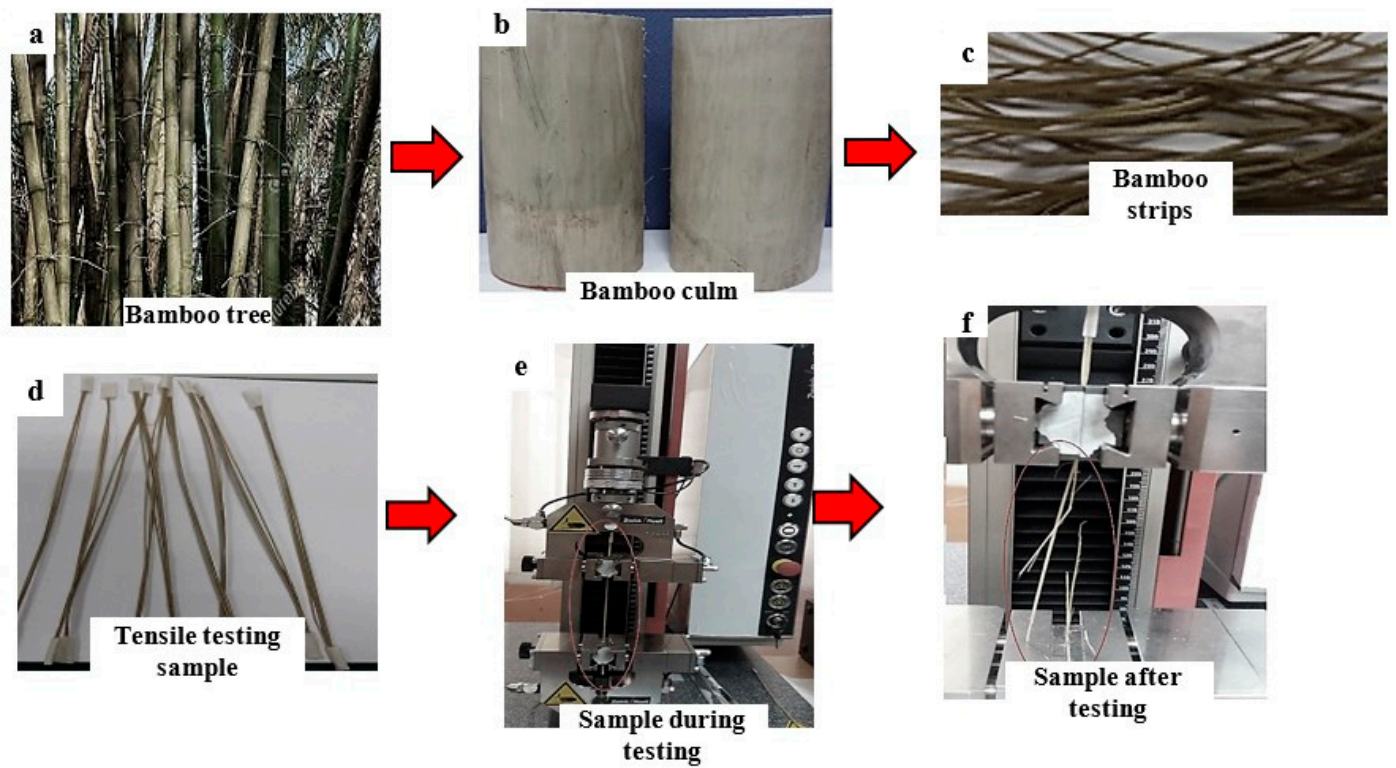

Figure 1. Schematic diagram of the preparation method used for the tensile testing samples: (a) the bamboo tree, (b) bamboo culm, (c) bamboo strips, (d) tensile testing samples, (e) sample during testing, and (f) sample after testing.

\subsection{Fiber Morphology}

The surface morphology of the bamboo strips after various alkali treatment conditions was examined with SEM (ZEISS/Carl ZEISS Sdn. Bhd.). The fractured surface of the tensile test samples was used with the SEM observations on an instrument operated at an accelerating voltage of $20 \mathrm{kV}$.

\section{Results and Discussion}

\subsection{Microstructure Characterization}

Figures $2-4$ show the surface morphologies of the 2 to $8 \mathrm{wt} . \% \mathrm{NaOH}$-treated single-cellulosic Buluh Semantan strips with a soaking time of $12 \mathrm{~h}$. The strips treated with different concentrations of $\mathrm{NaOH}$ had a different surface morphology. Figure 2a-c shows the SEM micrographs of the single-cellulosic bamboo fiber strips. The fractured cellulose fibers were observed for the low-alkali-concentration sample, suggesting an unsuitable concentration. Figure $3 a-c$ shows the individual cellular elements on the clean fiber surface after alkali treatment and relatively rough surfaces were observed on the single-cellulosic bamboo fibers. The researchers $[30,31]$ reported that the surface roughness increases with increasing aqueous $\mathrm{NaOH}$ concentration. Rough surface morphologies are typical for treated fibers because of the removal of hemicellulose and other surface impurities. Thus, alkali treatment can result in substantial changes in the fiber surface morphology, which can lead to an increase in the fiber wettability. 

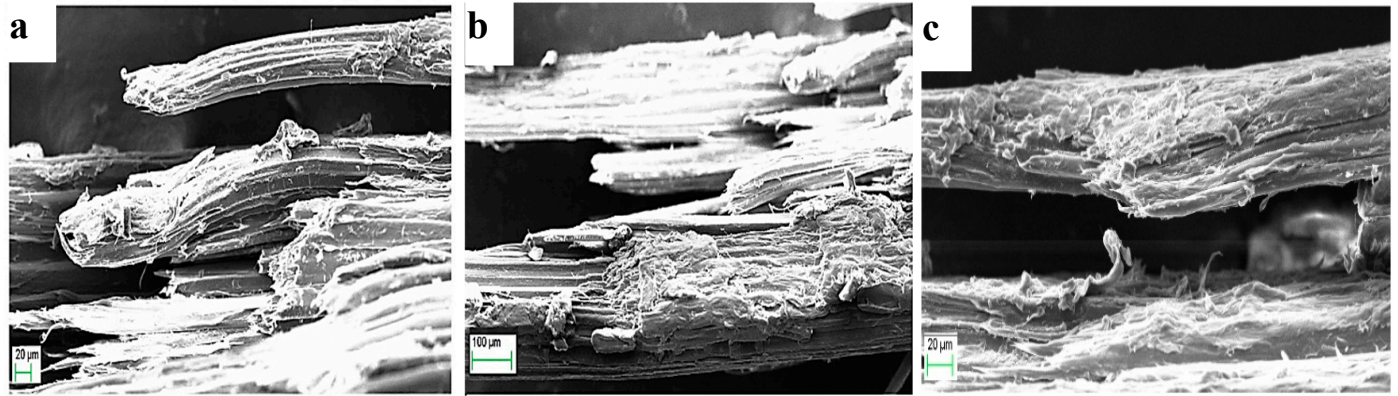

Figure 2. Microstructure of the surface of $2 \mathrm{wt} . \% \mathrm{NaOH}$-treated concentration the single-cellulosic Buluh semantan strips after soaking for $12 \mathrm{~h}$ in $2 \mathrm{wt}$.\% $\mathrm{NaOH}$ showing in $(\mathbf{a}-\mathbf{c})$ fractured fibers in different magnification.
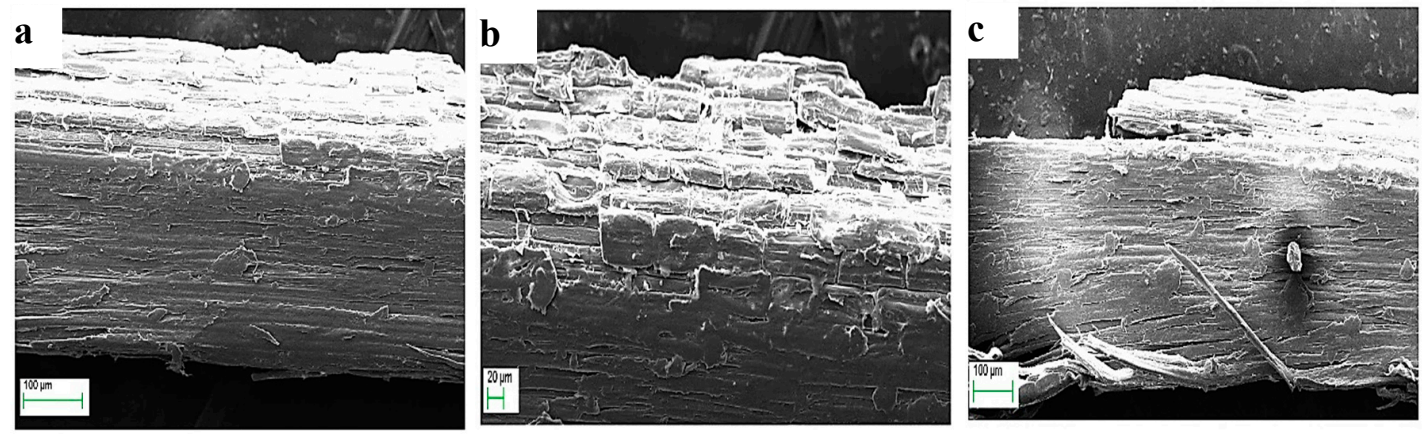

Figure 3. Microstructure of the surface of the single-cellulosic Buluh semantan strips after soaking for $12 \mathrm{~h}$ in $4 \mathrm{wt} . \% \mathrm{NaOH}$ showing in (a), and (b) b cellular elements on the clean fiber surface after alkali treatment in different magnification, (c) shows relatively rough surfaces.

The surface materials started to dissolve after treatment with the strong alkali concentrations (Figure 4a-c). Zhang et al. [26] reported that a decrease in fiber strength after treatment with high alkali concentrations can be attributed to the partial removal of cellulose. Holes and grooves were also observed, indicating the capability of the alkali treatment to remove very large amounts of soluble substances from the layers.
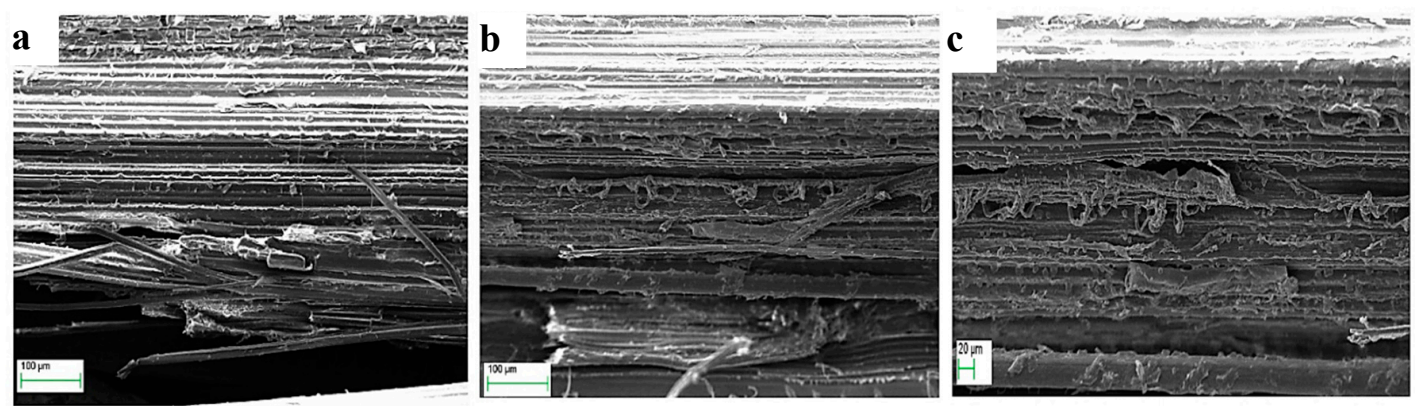

Figure 4. Microstructure of the surface of the single-cellulosic Buluh semantan strips after soaking for $12 \mathrm{~h}$ in $8 \mathrm{wt}$.\% $\mathrm{NaOH}$ showing in (a) fractured fibers, (b), and (c) holes and grooves on fiber surface.

Hence, an excessive alkali treatment and soaking time can damage the strength of single-cellulosic bamboo fiber strips, suggesting that these variables are also unsuitable for treating bamboo fibers (Figure 5). 
a

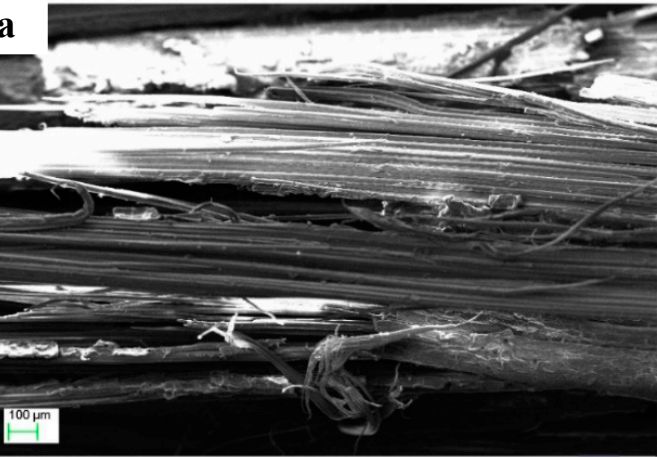

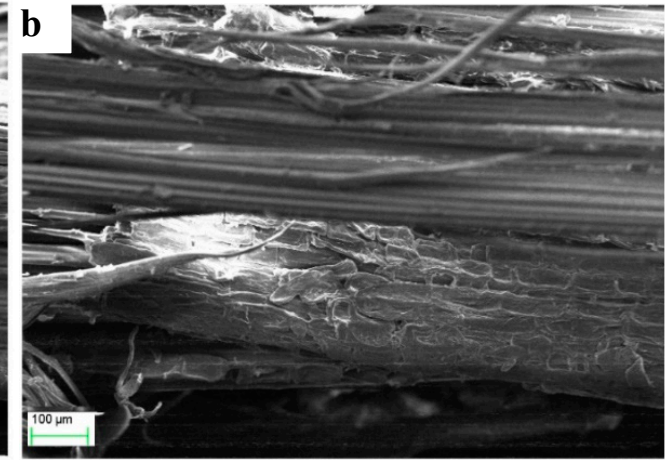

Figure 5. Microstructure of the surface of the single-cellulosic Buluh semantan strips after soaking for $18 \mathrm{~h}$ in $8 \mathrm{wt} . \% \mathrm{NaOH}$ showing in (a), and (b) damage the strength of fibers in different magnification.

Figure 6 shows the microstructure of the single-cellulosic bamboo strips after soaking for $18 \mathrm{~h}$ in 4 wt.\% alkali. The micrographs show a large number of regularly spaced holes or pits on the surface. These holes are possibly caused by the removal of fatty substances called tyloses from the fiber surface [31].
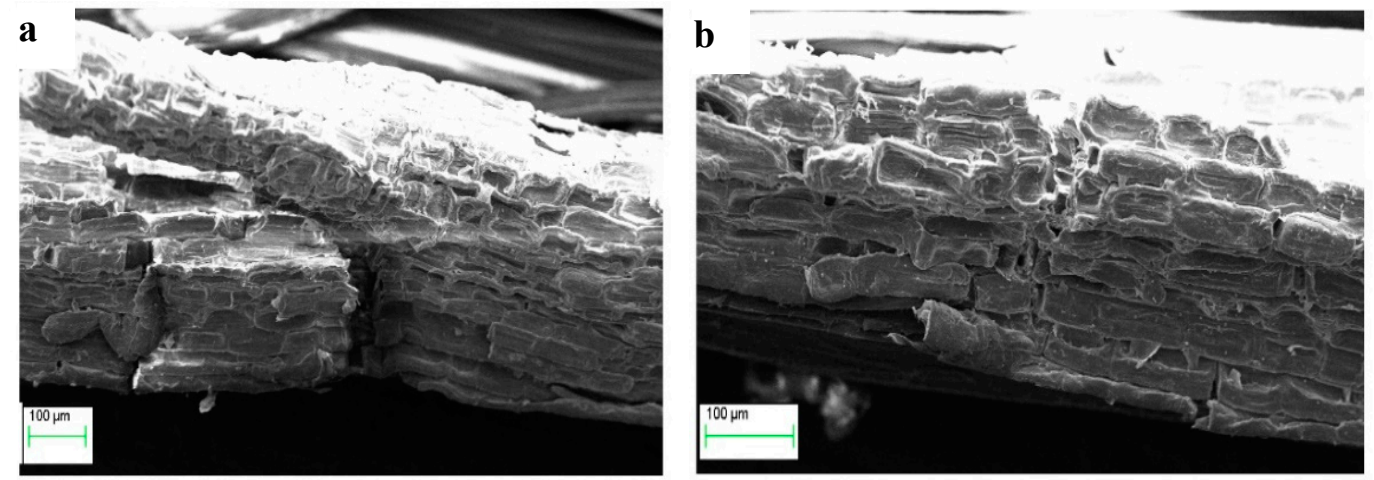

Figure 6. Microstructure of the surface of the single-cellulosic Buluh semantan strips soaked for $18 \mathrm{~h}$ in 4 wt.\% $\mathrm{NaOH}$ showing in (a), and (b) large number of regularly spaced holes or pits in different magnification.

\subsection{Tensile Properties}

Figure 7 shows the tensile-strength results for the fibers treated with different alkali concentrations and different soaking times, relative to those that underwent water retting. The $4 \mathrm{wt} . \% \mathrm{NaOH}$ treatment for $12 \mathrm{~h}$ had the best effect on the tensile strength of the bamboo fiber strips, whereas the high alkali concentration (i.e., $8 \mathrm{wt}$.\% treatment) for different soaking times yielded the lowest result herein. Similar observations have been reported by [1], who investigated the influence of alkali concentration on tensile properties of bamboo fiber. The fibers were alkalized with 1,4 , and $7 \mathrm{wt}$ \% $\mathrm{NaOH}$ solution for $1 \mathrm{~h}$. They found that the maximum tensile strength is achieved at $4 \mathrm{wt} . \%$ alkali treatment as a result of the low-alkali-concentration removal of hemicellulose, lignin, and other impurities that makes those fibrils more capable of rearranging themselves along the direction of tensile deformation, resulting in better packing of cellulose chains. Moreover, leaching of these non-cellulosic materials makes a rough topography that appears on the fiber surface, offering better interfacial adhesion with the matrix, causing an improvement in the fiber strength. They also found that the tensile strength decreased by $4 \%$ when they increased the alkali concentration to $7 \%$, as a result of weaker fiber with a high alkali concentration. The authors of [32] studied the soaking time effect on tensile strength of single pineapple leaf fiber. Their results showed that a 3-hour soaking time is insignificant for increasing tensile strength for both $3 \%$ and $6 \% \mathrm{NaOH}$ treatment. However, a 6-hour soaking time at $6 \mathrm{wt}$. $\%$ 
$\mathrm{NaOH}$ is able to remove hemicellulose and lignin and enhance surface area adhesion for fiber/matrix. Likewise, a 12-hour soaking time and $6 \mathrm{wt} . \% \mathrm{NaOH}$ treatment did not show much fluctuation and fall drastically to the lowest point, as the high alkali concentration may decrease tensile strength because it removes impurities, causes lignocellulosic degradation, and ruptures the fiber surface.

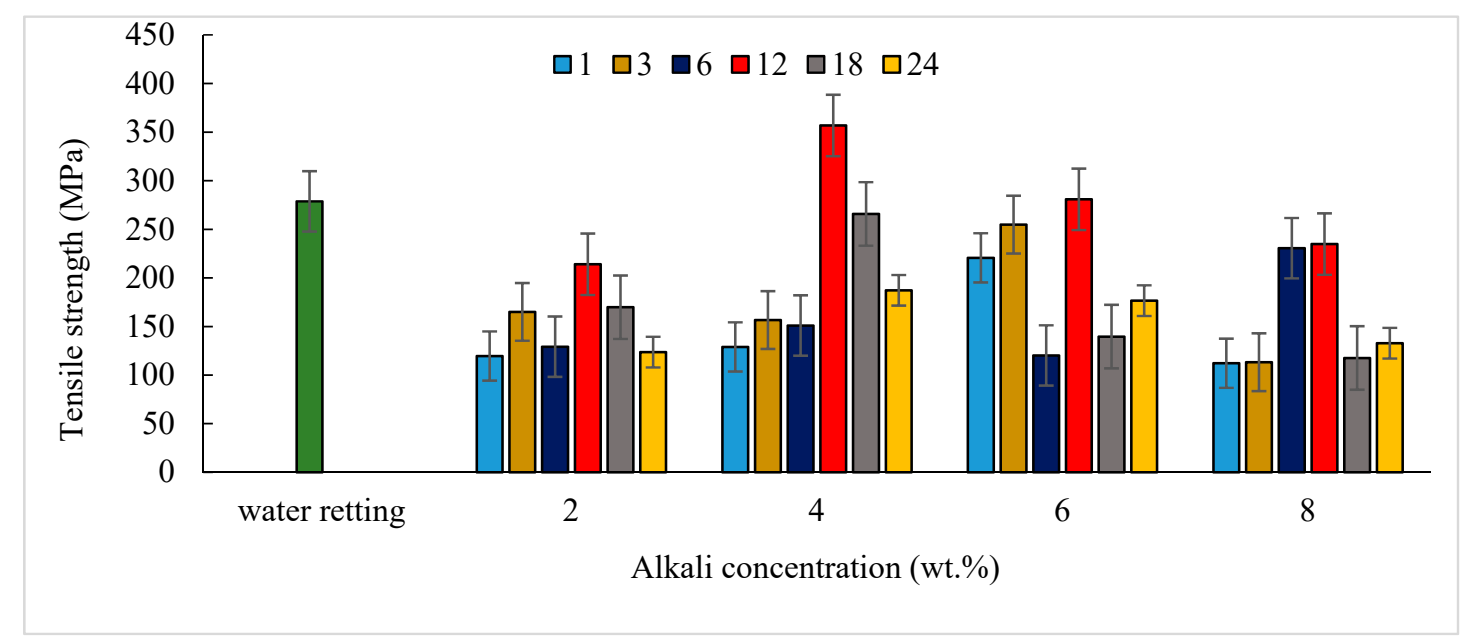

Figure 7. Tensile strength of the single-cellulosic bamboo fiber strips subjected to water retting and different alkali concentrations, for various soaking times.

As shown in Figure 8, the trend of the tensile modulus is similar to that of the tensile strength, and the tensile modulus increased smoothly up to the $6 \mathrm{wt} . \%$ concentration; moreover, the effect of the treatment time seemed to be significant. The optimum increase in the tensile modulus was achieved at a $6 \mathrm{wt} . \%$ concentration and $12 \mathrm{~h}$ of soaking. Similar observations were reported by [3]. They found the tensile modulus of banana fiber has been increase by $38 \%$ and $102 \%$ for 10 and $15 \mathrm{wt} . \%$ alkali concentration, respectively, and the same studies reported a decreased in the tensile modulus when increase alkali concentration to $20 \mathrm{wt} . \%$; due to degradation of cellulose, there is a reduction in tensile strength tenacity by $10 \%$ and tensile modulus by $66 \%$. Reddy and Gowda [33] reported that alkali treatment of sisal fibers improved the cellulose crystallinity and removed impurities, such as hemicellulose and lignin. The sisal fibers became much more ductile after the removal of some of the impurities, resulting in a substantially increased fiber stiffness due to the increased crystallinity of the hard cellulose. The enhanced tensile modulus of bamboo strips fiber is also due to the same factor.

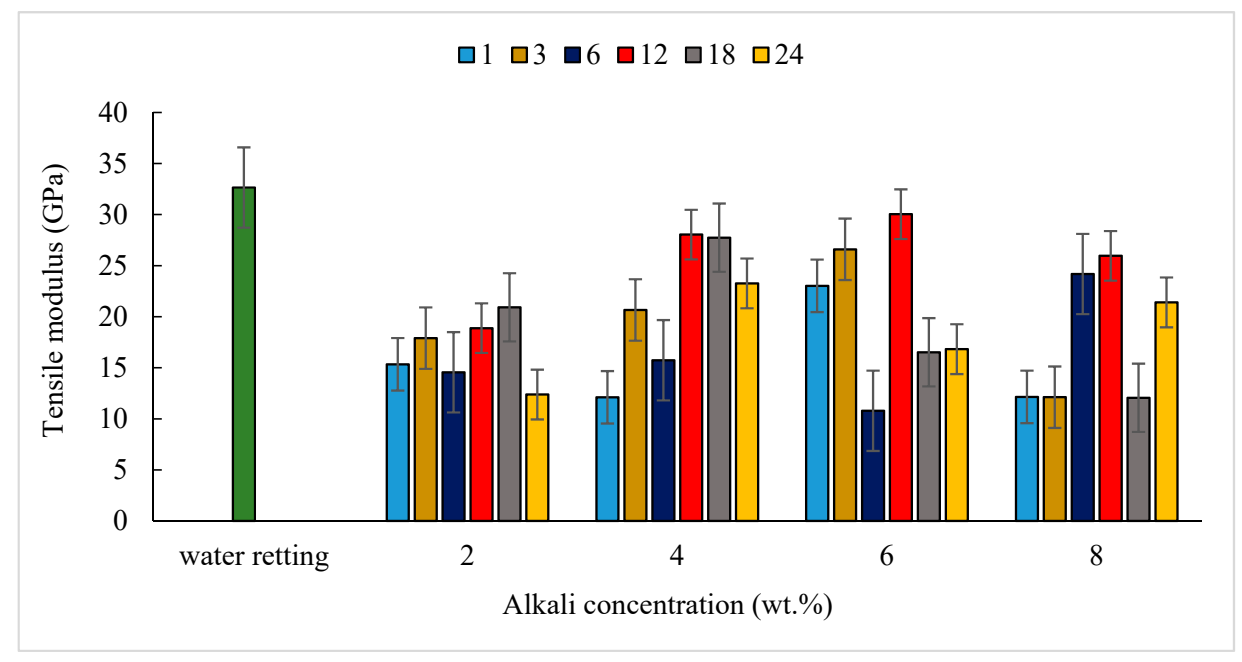

Figure 8. Tensile modulus of single-cellulosic bamboo fiber subjected to water retting and different alkali concentrations for various soaking times. 
Figure 9 shows the strain-at-break results for the different alkali concentrations for various soaking times, relative to those that experienced water retting. No significant differences in the strain rate were observed for the fibers with the $2,4,6$, and $8 \mathrm{wt} . \%$ treatments. The difference occurred between $0.7 \%$ and $1.6 \%$. The strain-at-break decreased slightly following the $4 \mathrm{wt} . \% \mathrm{NaOH}$ treatment. The data were consistent with an increase in the stiffness and brittleness of the fibers after the mid-phase of the alkali treatment in this study. The maximum strain-at-break of $1.602 \%$ was found for the fiber with the $4 \mathrm{wt} . \%$ alkali concentration and $12 \mathrm{~h}$ of soaking, whereas the minimum of 0.76 was found for the fiber with the $8 \mathrm{wt} . \%$ alkali concentration and $24 \mathrm{~h}$ of soaking. No obvious variations in the trend for the fracture strain as a function of the soaking time were established.

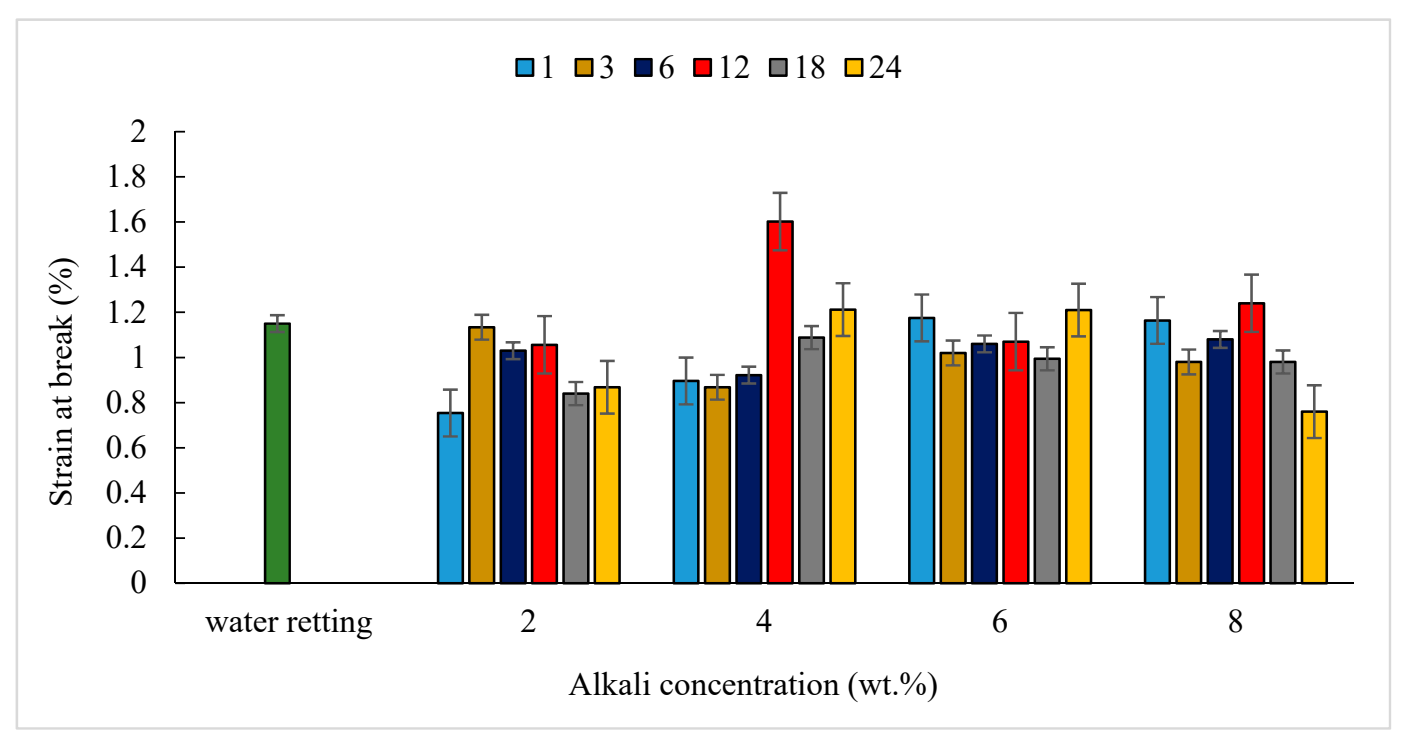

Figure 9. Strain-at-break of single-cellulosic bamboo-fiber strips subjected to water retting and different alkali concentrations, for various soaking times.

\section{Conclusions}

An experimental investigation was conducted in this study, to characterize the mechanical behavior and microstructure of single-cellulosic bamboo fiber strips. We found that the mechanical characteristics of the strips were affected by the various soaking times. The soaking time of $12 \mathrm{~h}$ resulted in optimized tensile properties, while increasing the soaking time to 18 and $24 \mathrm{~h}$ yielded the weakest performance herein. The tensile strength of the bamboo fiber strips was significantly improved after treatment with $4 \mathrm{wt} . \% \mathrm{NaOH}$ for $12 \mathrm{~h}$. In contrast, the fibers that experienced water retting only had a $28 \%$ increase in the tensile strength. Moreover, the tensile modulus of the bamboo fiber strips was significantly improved after treatment with $6 \mathrm{wt} . \% \mathrm{NaOH}$ for $12 \mathrm{~h}$, but the tensile modulus value at this condition was somewhat similar to that after water retting. We also found that an insufficient alkali solution decreased the tensile properties, whereas an excessively high $\mathrm{NaOH}$ solution can easily erode the fibers. The performance of the fibers was enhanced with the optimum drying and soaking times. The morphological changes determined from SEM observations indicated that alkali treatments at moderate concentrations enhanced the roughness of the Buluh semantan surface area, leading to an increase in the wettability. An excessive alkali concentration and soaking time damaged the fibers and subsequently affected their tensile properties.

Author Contributions: Writing-original draft preparation and investigation, A.A.S.; review and project administration, R.Z.; and investigation, C.H.A. All authors have read and agreed to the published version of the manuscript.

Funding: We would like to acknowledge the Universiti Kebangsaan Malaysia and Ministry of Education Malaysia for their financial support, under research grant GUP-2018-093. 
Conflicts of Interest: The authors declare no conflict of interest.

\section{References}

1. Wang, F.; Zhou, S.; Li, L.; Zhang, X. Changes in the Morphological-Mechanical Properties and Thermal Stability of Bamboo Fibers during the Processing of Alkaline Treatment. Polym. Compos. 2017, 39, 1-8. [CrossRef]

2. Tran, L.Q.N.; Fuentes, C.; Verpoest, I.; Van Vuure, A.W. others Tensile Behavior of Unidirectional Bamboo/Coir Fiber Hybrid Composites. Fibers 2019, 7, 62. [CrossRef]

3. Vardhini, K.J.; Murugan, R.; Rathinamoorthy, R. others Effect of alkali treatment on physical properties of banana fibre. Indian J. Fibre Text. Res. 2019, 44, 459-465.

4. Zubaidah, I.; Norfatriah, A.; Amali, Z.; Noorul, S.; Zuruzi, A.S. Preparation and Behavior of Bamboo Fiber-Reinforced Polydimethylsiloxane Composite Foams during Compression. Fibers 2018, 6, 91. [CrossRef]

5. Salih, A.A.; Zulkifli, R.; Azhari, C.H. Tensile Properties of Single Cellulosic Bamboo Fiber (Gigantochloa Scortechinii) Using Response Surface Methodology. J. Nat. Fibers 2020, 1-10. [CrossRef]

6. Singha, A.S.; Thakur, V.K. Fabrication and characterization of H. sabdariffa fiber-reinforced green polymer composites. Polym. Plast. Technol. Eng. 2009, 48, 482-487. [CrossRef]

7. Salih, A.A.; Zulkifli, R.; Azhari, C.H. Optimization of bamboo mesoparticle/nylon 6 composite mechanical properties using a response surface methodology. Int. J. Mater. Res. 2020, 111, 204-213. [CrossRef]

8. Salih, A.A.; Zulkifli, R.; Azhari, C.H. Water absorption behaviour and its effect on the mechanical properties of Gigantochloa scortechinii (buluh simantan). Int. J. Microstruct. Mater. Prop. 2019, 14, 184-201. [CrossRef]

9. Salih, A.A.; Zulkifli, R.; Azhari, C.H. Mechanical and morphological properties of bamboo mesoparticle/nylon 6 composites. Int. J. Mater. Res. 2019, 110, 130-136. [CrossRef]

10. Bahari, S.A.; Krause, A. Bamboo Particles-Polyvinyl Chloride Composites: Analysis of Particles Size Distribution and Composites Performance. J. Mater. Sci. Res. 2017, 6, 1. [CrossRef]

11. Gielis, J. Bamboo-The plant and its uses. In The Journal of the American Bamboo Society; Springer: Berlin, Germany, 2015; p. 252.

12. Kasmuric, M. Engineering Properties and Impact Resistance of Kenaf and Rice Straw Fibres Reinforced Concrete. J. Kejuruter. 2018, 1, 71-76.

13. Zhang, W.; Yao, X.; Santosh Khanal, S.X. A novel surface treatment for bamboo flour and its effect on the dimensional stability and mechanical properties of high density polyethylene/bamboo flour composites. Constr. Build. Mater. 2018, 186, 1220-1227. [CrossRef]

14. Ghoushji, M.J.; Eshkoor, R.A.; Zulkifli, R.; Sulong, A.B.; Abdullah, S.; Azhari, C.H. Energy absorption capability of axially compressed woven natural ramie/green epoxy square composite tubes. J. Reinf. Plast. Compos. 2017, 36, 1028-1037. [CrossRef]

15. Oushabi, A. The pull-out behavior of chemically treated lignocellulosic fibers/polymeric matrix interface (LF/PM): A review. Compos. Part B Eng. 2019, 107059. [CrossRef]

16. Pappu, A.; Patil, V.; Jain, S.; Mahindrakar, A.; Haque, R.; Thakur, V.K. Advances in industrial prospective of cellulosic macromolecules enriched banana biofibre resources: A review. Int. J. Biol. Macromol. 2015, 79, 449-458. [CrossRef]

17. Singha, A.S.; Thakur, V.K. Synthesis and characterization of pine needles reinforced RF matrix based biocomposites. J. Chem. 2008, 5, 1055-1062. [CrossRef]

18. Amel, A.B.; Paridaha, M.T.; Sudin, R.; Anwar, U.M.K.; Ahmed, S.H. Effect of fiber extraction methods on some properties of kenaf bast fiber. Ind. Crops Prod. 2013, 46, 117-123. [CrossRef]

19. Sugiman, S.; Setyawan, P.D.; Anshari, B. Effects of alkali treatment of bamboo fibre under various conditions on the tensile and flexural properties of bamboo fibre/polystyrene-modified unsaturated polyester composites. J. Eng. Sci. Technol. 2019, 14, 26-46.

20. Orue, A.; Jauregi, A.; Unsuain, U.; Labidi, J.; Eceiza, A.; Arbelaiz, A. The effect of alkaline and silane treatments on mechanical properties and breakage of sisal fibers and poly (lactic acid)/sisal fiber composites. Compos. Part A Appl. Sci. Manuf. 2016, 84, 186-195. [CrossRef]

21. Dai, B.; Wang, Q.; Yan, W.; Li, Z.; Guo, W. Synergistic compatibilization and reinforcement of HDPE/wood flour composites. J. Appl. Polym. Sci. 2016, 133. [CrossRef] 
22. Hashim, M.Y.; Amin, A.M.; Marwah, O.M.F.; Othman, M.H.; Yunus, M.R.M.; Huat, N.C. The effect of alkali treatment under various conditions on physical properties of kenaf fiber. In Proceedings of the International Conference on Materials Physics and Mechanics, Langkawi, Malaysia, 23 July 2017; pp. 1-15.

23. Wong, K.J.; Yousif, B.F.; Low, K.O. The effect of alkali treatment on the interfacial adhesion of bamboo fiber. J. Mater. Des. Appl. 2010, 224, 139-148.

24. Behera, S.; Prasad, N.; Kumar, S. Study of Mechanical Properties of Bamboo fibers before and after Alkali Treatment. Int. J. Appl. Eng. Res. 2018, 13, 5251-5255.

25. Essabir, H.; Boujmal, R.; Bensalah, M.O.; Rodrigue, D.; Bouhfid, R.; el kacem Qaiss, A. Mechanical and thermal properties of hybrid composites: Oil-palm fiber/clay reinforced high density polyethylene. Mech. Mater. 2016, 98, 36-43. [CrossRef]

26. Zhang, K.; Wang, F.; Liang, W.; Wang, Z.; Duan, Z.; Yang, B. Thermal and Mechanical Propertiesrof Bamboo Fibe Reinforced Epoxy Composites. Polymers 2018, 10, 608. [CrossRef]

27. Chen, H.; Yu, Y.; Zhong, T.; Wu, Y.; Li, Y.; Wu, Z.; Fei, B. Effect of alkali treatment on microstructure and mechanical properties of individual bamboo fibers. Cellulose 2017, 24, 333-347. [CrossRef]

28. Mishra, S.; Mohanty, A.K.; Drzal, L.T.; Misra, M.; Parija, S.; Nayak, S.K.; Tripathy, S.S. Studies on mechanical performance of biofibre/glass reinforced polyester hybrid composites. Compos. Sci. Technol. 2003, 63, 1377-1385. [CrossRef]

29. Manalo, A.C.; Wani, E.; Zukarnain, N.A.; Karunasena, W.; Lau, K. Effects of alkali treatment and elevated temperature on the mechanical properties of bamboo fibre-polyester composites. Compos. Part B Eng. 2015, 80, 73-83. [CrossRef]

30. Liu, Y.; Ma, Y.; Yu, J.; Zhuang, J.; Wu, S.; Tong, J. Development and characterization of alkali treated abaca fiber reinforced friction composites. Compos. Interfaces 2019, 26, 67-82. [CrossRef]

31. Reddy, K.O.; Shukla, M.; Maheswari, C.U.; Rajulu, A.V. Mechanical and physical characterization of sodium hydroxide treated Borassus fruit fibers. J. For. Res. 2012, 23, 667-674. [CrossRef]

32. Asim, M.M.; Jawaid, K.A. Effect of Alkali treatments on physical and Mechanical strength of Pineapple leaf fibres. Mater. Sci. Eng. 2018, 290, 1-6. [CrossRef]

33. Mohan, C.H.K.; Reddy, G.G.V.; Gowda, C.M. Mechanical Properties of Untreated and Alkali Treated Sida Acuta Stem Fibre. Int. J. Sci. Eng. Res. 2015, 6, 1352-1359.

(C) 2020 by the authors. Licensee MDPI, Basel, Switzerland. This article is an open access article distributed under the terms and conditions of the Creative Commons Attribution (CC BY) license (http://creativecommons.org/licenses/by/4.0/). 